\title{
Persuasive Discourse in EFL Debate
}

\author{
Maija Metsämäki \\ School of Humanities, University of Eastern Finland, Finland \\ Email: maija.metsamaki@uef.fi
}

\begin{abstract}
The aim of this article is to investigate the use of persuasive strategies in multinational university students' EFL debate, in which a group of multinational students had to act out the roles of proponents and opponents in debates carried out in an institutional setting. Their use of persuasive discourse was analyzed by using the principles based on Aristotelian rhetoric. According to the results, the students were able to use rhetorical devices, to express ethos, pathos and logos, in their argumentation. They were able to use logical reasoning, give examples and statistical information, and support their arguments with evidence. Their persuasive strategies consisted of restructuring, repetition, questions, appeals, and intonational, assertive use of voice. A comparison of crosscultural differences showed that the non-Finnish students used logical reasoning, restructuring, and appeals more frequently than the Finnish students in their L2 debating.
\end{abstract}

Index Terms - persuasive discourse, rhetorical devices, debating, crosscultural differences

\section{INTRODUCTION}

The aim of this article is to investigate elements of persuasive discourse in EFL debate. The genre of persuasion is amongst the oldest styles of discourse, studied and practised already in the antiquity. In the first part of my article I will present the background of my study and the reasons for it. My observations concerning university students' limited oral skills in English led me to investigate the possible reasons for the students' problems. Being aware of the dilemma known as the Finnish communication reticence (Sallinen-Kuparinen 1986; Sallinen 1994), I wanted to create a challenging and demanding language testing situation with exact instructions, which would facilitate the students' efforts to cope in English. After several efforts I noticed that role-games would help me achieve positive results. Furthermore, debating had become a popular form of practice for language teaching and this led me to develop the study in question. Accordingly, the empirical part of my research project is an analysis of the use of persuasive discourse in debates in which a multinational group of university students acts out either the proponents' or the opponents' roles in English. In this article, my main interest is in the investigation of persuasive discourse and crosscultural differences among the students of different nationalities. My research questions are:

1) What kinds of persuasive devices do the students have available in a demanding debating situation in English?

2) What kinds of crosscultural differences are there in Finnish and non-Finnish students' use of persuasive discourse?

In persuasive communication, the speakers try to influence the behaviour of others with the aim of trying to make them alter their opinions, beliefs, attitudes, and values. The role of the speaker in persuasion is the most important part of the process, but in addition, the nature and structure of the message and the role of the audience are also significant. Persuasion is successful, if it leads to attitude change (Simons et al,. 2001).

\section{THEORETICAL BACKGROUND}

I will start my theoretical framework with a historical survey of the origins of persuasive discourse and then investigate the central elements of rhetoric. After that I will explain my data and methods before presenting the empirical part of the study.

\section{A. History of Persuasive Discourse}

The history of persuasive discourse dates back to the antique times, practised first in Greece (Plato and Aristotle) and then in Rome (Cicero), where the main purpose of rhetorical studies was to become a good orator in political assemblies. After the fall of the Roman Empire in 275 the study of rhetoric fell into oblivion and was not practised until the 16th century when argumentation studies were reintroduced as an independent academic discipline. Rhetoric has often been regarded as belonging to the language of politics and religious discourse. Since the second half of the 19th century, courses on writing and public speaking inspired by classical rhetoric were introduced in North America and Europe, and now many universities provide courses on debating and argumentation based on classical rhetoric (van Eemeren \& Grootendorst, 2005). I will present the main principles of Aristotelian rhetoric ethos, pathos, and logos in more detail in Section II.b below. Hovland, one of the earliest modern researchers who has done versatile research on persuasion and attitude change, developed the Social Judgment Theory concerning attitude change with his collaborators at Yale University in the 1950s (Hovland, Janis, and Kelley, 1953). Social Judgement Theory states that one has a statement or message and that one either accepts or rejects it on the basis of one's cognitive map. A part of the theory is Source Credibility Theory according to which people are more likely to be persuaded when the source presents itself as credible. 
Hovland developed the Social Judgement Theory further with M. Sherif (1961), interpreting that individuals have three zones in which they accept or reject specific messages or attitudes, viz. acceptance, rejection, and non-commitment. C. \& M. Sherif \& Nebergall (1965) investigated the Social Judgement Theory further and emphasized the difficulty of position-taking from the persuadee's point of view.

Since the late 1950s the study of argumentation has gradually developed from a marginal part of logic and rhetoric into a genuine and interdisciplinary academic discipline. As an example, Roloff and Miller (1984) compiled a collection of articles addressing the effects of persuasion on various fields of life ranging from Marketing and Persuasion to Political Campaigns. Similarly, Burgoon \& Bettinghaus have investigated Persuasive Message Strategies (1984). Argumentation has become an important field of studies, as seen in van Eemeren and Houtlosser's important volume Argumentation in Practice (2005) which introduces useful theoretical perspectives. Tannen, (1999, pp. 215-223) indeed states that the ways of expressing agreement and disagreement are different in different cultures and emphasizes the importance of argumentation studies. Many conflicts could be avoided if awareness of cross-cultural differences could be increased.

The notion of discursive power is frequently connected to persuasion. Power is always part of language use and if we think of persuasive discourse where we intentionally emphasize the influence of language, we agree that persuasion and power go hand in hand (Fairclough, 2001). In his The Power of Persuasion: How We're Bought and Sold (2003) Levine emphasizes that the content of the persuasive message is only one part of the persuasive process: how it is said, who says it, and where it is said are other important aspects in it. In addition to awareness of persuasive strategies the speakers should know how to behave in the oral persuasive situation and what kind of voice and tone one should use, in other words, the speakers should also be aware of the paralinguistic tools (see Metsämäki, 2011).

\section{B. Elements of Persuasive Discourse}

I will first present Aristotle's (1926) own definition in which he compares rhetoric with other fields of science and the arts:

Rhetoric can be defined as the faculty of discovering the possible means of persuasion in reference to any subject whatever. (This is the function of no other of the arts, each of which is able to instruct and persuade in its own special subject: thus, medicine deals with health and sickness). . But Rhetoric so to (speak) appears to be able to discover the means of persuasion in reference to any given subject. That is why we say that as an art its rules are not applied to any particular definite class of things. (Aristotle 1926:p. 15)

What this shows is that awareness of rhetoric helps us resort to its tools in many fields of society. The following section will define the key terms of persuasion in more detail. Aristotle (1926) distinguishes three kinds of proofs or structural principles: persuasion by moral character (ethos), persuasion by putting the hearer into a certain emotional frame of mind (pathos), and persuasion by the speech itself (logos). On the basis of this analysis, we can draw the following conclusion: persuasive talk consists of the speaker, the message, and the listener(s)/audience. All elements are important, but the role of the speaker is most frequently considered to be the most significant of the process.

Ethos (Greek for character) refers to the trustworthiness or credibility of the speaker. Ethos is often conveyed through the tone and style of the message (Aristotle, 1997). According to Cockcroft (2005, p. 16), ethos can be divided into two aspects: personality and stance. Personality is recognizable in any spoken exchange which gives us confidence in the person we are talking to, whereas the notion of stance refers to a wider framework of attitudes, a sense of the persuader's position or viewpoint about what is being discussed (Cockcroft, 2005). Aristotle (1997) identifies the following qualities as communicating ethos: trust, benevolence and constructive competence, which means that success has been achieved with the help of right vocabulary, intonation, and structural organization. In addition, ethos involves that the persuader has taken a persuader's stance and has positioned him/herself as a persuader.

Pathos (Greek for suffering or experience) is often associated with emotional appeal. For achievement of success in persuasion, emotional appeals both towards audience and topic are needed. Emotional engagement can be created by a variety of linguistic means, the right language choice, and through imagination (Cockcroft, 2005:, p. 17).

According to Aristotle, logos means persuading by the use of reasoning. The Greek word logos means word and it refers to the internal consistency of the message, the clarity of the claim, the logic of its reasons, and the effectiveness of its supporting evidence. The impact of logos on the audience is sometimes called the argument's logical appeal (Aristotle, 1997). Dictionaries give a wide range of meanings for the word logos, and at different periods it has had many meanings directly relevant to rhetoric. In many contexts it has been defined as plea, arguments leading to a conclusion, thesis, reason or ground of argument, inward debate, speech, and verbal expression (Cockcroft, 2005:, p. 17).

\section{Persuasive Message}

According to Aristotle's definition, rhetoric is the ability, in each particular case, to see the available means of persuasion (Aristotle 1997). The persuasive message should consist of a clearly uttered main issue and the ideas supporting it. It should be rational and logical, it should be emotional and it should give evidence, and it should consist of logical statements. Depending on the topic, a persuasive message frequently contains appeals to authorities and famous people (Burgoon \& Bettinghaus, 1984:, pp. 141-147).

Aspects of persuasive language use have been studied in various fields, not only in rhetoric. Speech act theory was 
developed by philosophers Searle (1969) and Austin (1962). Austin (1962) described utterances as performative or constative and defined communication as 'a co-operative venture between writer/speaker and one (or more) reader(s)/listener(s)' (p. 951962: 94-101). In Austin's (1962) view this communication can be seen as either locutionary (the speaker), illocutionary (the message) or perlocutionary act (effect of the message): while illocutionary speech acts are expressive, descriptive, directive ways of making statements and conveying information, perlocutionary speech acts are intended to achieve certain results in a listener. The persuader will be able to draw on these speech acts to fulfill Cicero's three 'rhetorical duties': to teach, to delight, and to move (Cockcroft, 2005, p. 22). Tarasti (2008) explains persuasive discourse through Searle's speech act theory: a locutionary act corresponds to the grammatical statement proper, and the notion of illocution means the utterance in a certain situation with the aim to act (2008, p. 6). The final impression of the locution in the receiver/audience is perlocution (Tarasti, 2008, p. 6). One of the most accessible theories of successful speech derives from the Conversational Maxims defined by H. P. Grice (1975): these include the Maxim of Quantity 'give exactly the amount of information which is appropriate', the Maxim of Quality 'be truthful', the Maxim of Relation 'be relevant', and the Maxim of Manner 'be clear'. These maxims have been called the cooperative principle in persuasive discourse, and awareness of these principles when seeking to achieve success in conversation is important. It has also been a concern of Politeness Theory, a field the development of which started in 1967 when Erving Goffman noted the importance of face in conversation: positive face reflects our basic need to be approved of and negative face our need not to be imposed on. In successful conversation/persuasion we need to avoid face-threatening acts by respecting social distance and status (Goffman, 1981).

Persuasive discourse strategies used in the debates consist of the following ones: stating the idea and supporting it, being rational, judging syllogisms, using evidence, logical reasoning, statistical information, facts, examples, repetition, questions, and appeals (Roloff \& Miller, 1984, pp.: 143-148).

\section{Audience/Listeners/Opponents}

While the speaker plays the main role in persuasive interaction, the role of the listeners/opponents/audience is also very important. The communicative situation may be a dialogue or a co-operative session. The forum may be a workplace or a public domain, formal or informal. The way in which the persuasive message is received depends on the character of the situation and the listeners. To be successful, the evidence used in the message should be clear and organized. Whether rational messages are more effective than emotional ones depends on the situation and the audience. The use of evidence is dependent on the topic of the message, age, sex, education, ethnicity, and other similar dimensions. Evidence persuasive to one audience would not be persuasive to others (Burgoon \& Bettinghaus 1984), and there occur differences in receivers' reactions (Ylikoski, 1987). Hutchby's approach (1996, pp. 20-22) to the role of the recipient differs from the classical approach by Aristotle. Hutchby (1996) sees the argument as an interactional process and he focuses on the role of the opponent in debating situations. In L2 teaching and role games in particular, the role division may help the participants to take their stands and overcome the linguistic breakdowns (Fulcher \& Davidson, 2007).

\section{E. Debate}

As mentioned in the previous section, the history of persuasive discourse goes back to the days of antiquity, as does the history of debating. Sons of rich aristocratic families had to study debating at the universities in order to learn argumentation skills. Debating consists of several types of debates and the best known genre of debate is parliamentary debate. Presidential and political debates form one of the most popular types of debates. According to Aristotle (1997), rhetoric means the ability to perceive the convincing thing in every issue. The traditional definition claims that debating means skills of confirming, persuading or appealing, but it can also be understood as skills of argumentation or reasoning. The main aim of the studies is to learn how to act in the debating situation as well as in the roles of proponent and opponent. Dialectics was used as a synonym for rhetoric and Aristotle identified them as logical ways of thinking, which aim at reliability, whereas logic and philosophy aim at truth.

Aristotle (1997) divides rhetoric into three parts: 1) political, 2) judicial, and 3) representing. Political speeches deal with the measures, which should be implemented or omitted in the future. Judicial speeches aim at clarifying the truth in the measures which have been done in the past. Explanatory speeches concentrate on praising or accusing a person or a matter at present.

Debate can be defined as assertive interaction between two parties, affirmative and negative, with different views on given topics (Ylikoski, 1987). The number of participants may vary. There may be two persons or two groups, or one person may debate against a group, yet the main idea is that the parties are either 'for' (pro) or 'against' (con) the theme given. There may be a moderator acting as a chair, but sometimes the debate is conducted without any leader. The most common type of debate deals with opinions or beliefs (Kakkuri-Knuuttila \& Halonen, 2007).

\section{RESEARCH QUESTIONS, DATA, AND METHODS}

\section{A. Research Questions}

The aim of persuasive speech is to try to influence the listeners and make them persuaded of the credibility of the speaker. My research questions were: 
1. What kinds of rhetorical means are the students able to use in a demanding debating situation in English? (RQ1)

2. What kinds of crosscultural differences are there in Finnish and non-Finnish university students' use of persuasive discourse? (RQ2)

\section{B. Data Collection}

The study was implemented at the Department of Clinical Medicine and Nutrition of the former University of Kuopio, Finland, in spring 2006. The subjects of the data consisted of $34(\mathrm{~N}=34)$ multinational university students of medicine, both Finnish $22(\mathrm{~N}=22)$ and foreign $12(\mathrm{~N}=12)$ students. The language of the course was English as a first foreign language (EFL). The proficiency level of the students was higher intermediate or advanced level. The group had completed a two-semester MPH (Master of Public Health) course at the University of Kuopio and the language of the course had been English. During their course, the students, under the guidance of experts from different fields, had dealt with most of the essential issues related to the field of Public Health. The methods of instruction had included lectures, group discussions, individual presentations, and essay writing. The final part of the course was participation in a debate, which was videorecorded. The course leader had chosen the following topics for the final debates:

- Restriction of alcohol under the age of eighteen encourages alcohol abuse among young people

- Abstinence is the best possible solution to prevent HIV/AIDS

\section{Method}

The students had been divided into four groups, but they did not know the themes of the debates. Upon entering the videoing room, they were subdivided into two groups: 'For' and 'Against'. Two groups debated the theme on 'Alcohol legislation in Finland' and two groups on the theme of 'HIV/AIDS'. The topics of the debates were given to the students right before they entered the room. After a short introduction to the theme and the research project, the students were asked to start the debate. There was no moderator nor a chair in the debates. The leader of the course, the video technician, and I were present in the videoing room during the recording.

The debates were transcribed in a way that allows analysis of both discursive and non-discursive features. For the purposes of this article, the data were analyzed on the basis of the context, speech acts, rhetorical techniques, and argumentation. Participation framework was compiled on the basis of the length of the turns of the speakers and the groups.

In order to find answers to RQ1, a list of persuasive discourse strategies was compiled. Finally, a comparison between the use of persuasive discourse strategies between Finnish and non-Finnish students was made.

After the debate sessions the students could view the videos and they were given questionnaires with questions concerning the debate session, their previous studies of English, their own evaluation of their proficiency level in English, the problems they had probably had, and their opinions about possible courses of argumentation. The topics of the debates did not please all students. A new debating session with new themes was provided for the students, but only three foreign students were present.

\section{Results}

The aim of the study was to examine what kinds of elements of persuasive discourse the multinational group of students would use while debating in English. Furthermore, crosscultural differences in students' debating were studied. On the basis of the data it can be concluded that the students had in their use several elements of persuasion as defined by Aristotle. Examples of the use of ethos, pathos, and logos will be given in the analysis in the next section. In addition, the students were able to use collaborative strategies and paralinguistic tools, such as intonational use of voice, gestures, eye-gaze, facial expressions, head and body movements, smile, and laughter (see Metsämäki, 2011).

\section{A. Analysis of the Debates}

In argumentative talk, the first step that the participants have to take, is to express the goal of the debate or the argument. After this, the goal, the main issue, must be supported by different rhetorical means (Burgoon \& Bettinghaus 1984). The utterances have to be logical, short, and clear. The structure of debating must be very concise and logical, and the arguments have to be clearly stated and assertive.

The subgroups consisted of 4-5 participants and in each group there was at least one non-Finnish student. The general atmosphere showed a joint effort to create an active debate and the participants managed to work like cooperative teams. The average length of the debates was 11.30 minutes. There were not any long pauses in the debates, and the pauses and breakdowns were mainly due to lexical problems. Problems were solved by restructuring and collaborative discussions. Debates 1 and 2 dealt with alcohol legislation in Finland and Debates 3 and 4 dealt with prevention of HIV/AIDS. The initial turn in Debates 1 and 2 was taken by a non-Finnish student in Group 'Against'. In Debates 3 and 4, the initial turn was taken by a Finnish student in Group 'For'. In a way, the first speaker took the chairing role for the whole debate.

According to the results, the students were able to use the following means of persuasive discourse in their debates: logical reasoning, repetition, questions, repeated questions, restructuring and appeals. The following table was compiled to elicit the students' use of these elements. The most frequent forms of persuading were logical reasoning $(\mathrm{N}=61)$ and 
restructuring ( $\mathrm{N}=55)$, and this was apparent in both Finnish and non-Finnish groups. In the order of frequency, the next group was the use of appeals $(\mathrm{N}=31)$ which is a very important element in rhetorical discourse. Repetition (13), questions (13), and repeated questions (10) were the next means of persuasion. The following table indicates to what extent the students were able to use the elements of persuasive discourse in their debates.

TABLE 1.

USE OF ELEMENTS OF PERSUASIVE DISCOURSE IN FINNISH AND NON-FINNISH UNIVERSITY STUDENTS' DEB ATE.

\begin{tabular}{|l|l|l|l|}
\hline Form of persuasive discourse & Finnish & Non-Finnish & All participants \\
\hline Logical reasoning & 32 & 29 & 61 \\
\hline Repetition & 7 & 6 & 13 \\
\hline Questions & 9 & 4 & 13 \\
\hline Repeated questions & 7 & 3 & 10 \\
\hline Restructuring & 26 & 29 & 55 \\
\hline Appeals & 13 & 18 & 31 \\
\hline Total & 94 & 89 & 183 \\
\hline
\end{tabular}

In the following analysis, I will first discuss the use of rhetorical means by giving examples illustrating the persuasive features based on Aristotelian principles. The abbreviations refer to the following words: $D=D e b a t e, G=$ Group, F = For, A = Against.

I will start the rhetorical analysis by analyzing the use of ethos. According to Cockcroft, the focus of ethos is on the persuader and his/her personal stance, and the best way to understand stance is to stretch the imagination and powers of empathy by trying to speak in such a way that the possible audience is convinced (Cockcroft, 2005:, p. 191). An appeal to ethos can be seen in the following example in the Dutch student's appeal to Dutch drinking habits and in her way of defending Dutch youngsters:

Ex. 1

D2 A1 Yeah I found data about the difference between the USA drinking habits and the Netherlands and there was in . . . there that er in the Netherlands they drink LESS than in the US and that's because er the young people are not so courageous about how it is to drink because it's . . they are allowed to in the Netherlands and in the USA it's a big deal for them . . . because they . . . they can do it . . . and so they do everything to have a night together to drink a lot ...

By taking this example of her own country, the Dutch student has a safe ground to position herself as an opponent in the debating situation concerning Finnish drinking habits. In the next example, a Finnish male student from Group 'For' wants to check the credibility of the message and makes a clarifying question. This shows that student F2 uses double questioning: the student presents first a reinforcing question with a question tag and then an assertive question/statement in order to be convinced of the alcohol regulations in the Netherlands. The sequence is also a good example of a short argument - counterargument sequence. The above excerpt and the following example show both ethos and pathos, which is indicated also by very assertive use of voice:

Ex 2

D2 F2 But there ARE age restrictions in the Netherlands, aren't there?

A2 ah . . sixteen

F2 yeah but there ARE restrictions. . .

Pathos, or emotional appeal, seeks to appeal to the needs, values, and emotional sensibilities of the audience. Argumentation emphasizes reason, but when used properly there is often a place for emotion as well. According to Cockcroft (2005,: p. 17), emotional engagement or pathos includes the need to orient emotional appeals towards the audience and the topic. In brief, persuasion is implemented by using rhetorical speech and by putting the hearer into a certain emotional frame of mind. The link between emotive source, persuader, and audience constitutes engagement, and although individual experiences of emotion vary, most people can access a wider range of emotions through the power of imagination. This can be seen in the following example, in which the speaker is a female student who tries to illustrate the feelings and emotions of a young girl in a difficult and delicate situation. The delicate theme refers to the listeners' emotions, and at the same time it takes the topic into account. The question 'Do you think that ..' is an additional marker of emotional appeal:

Ex. 3

D3 F1 we are also discussing about the abstinence as a way of prevent ..... and if you think like . . the thirteen ... the twelve or thirteen-year-old girl . . . if they are like . . . er . . have a boyfriend who has something . . is fifteen year old . . . like normally it is . . that . the boy is older than the girl . . . do you think that they are ready to say the girl . . the boy who maybe doesn't want to use the condom because it's uncomfortable or some other stupid reasons . . and . . .do you think that this girl has the guts to tell the boy that I don't want to have sex if you don't use the condom . . . it's like ... because it's very sensible situation and th . . . and the girl wants to be cool and say that it's okay it's okay we are going to have sex . .

The following example shows how the speaker uses pathos by trying to change the beliefs of the audience by referring to young people in developing countries and by using the effective means of persuading by three-word-sequencing, uttering it in an expressive and effective speech rhythm. Her intonation was thus assertive.

Ex. 4 
D4 F2 ... and of course ... er ... trying to . . er . . change the way . .er . . young people in developing countries ... er . . . feel about sex in . . in younger age . . trying to . .er . . change their beliefs and their thoughts would be a good idea . . in in . . in terms of . . making them think that IT'S NOT COOL, IT'S NOT NICE, IT'S NOT FUNNY ... IT'S NOT ANYTHING that you should do when you're young . . er . .

In Debate 3 concerning HIV/AIDS and discussing abstinence as the best solution to prevent it, Student F1 tries to appeal to emotions when trying to find the best ways to make young people postpone their sexual experiences.

Ex. 5

D3 F1 do you think that . . like . . okay . . do you think about like in western countries and there are lots of youngster who are like twelve or thirteen year . . . do you think . . that this is the best way or . . or do you think that they are ready to . . . use condoms . . . they are ready to have the sexual intercourse ... or the best way for them is the abstinence . . . of course you can promote that in many other ways then . . like don't sex . . . you can ... you can make reasons for that like ... okay . . .that . . . you .. first thing what you have to . . it's not cool to have sex when you are twelve ... nowadays lot of the young they think that it's very cool to have sex when you are twelve or thirteen year . . so . . . this abstinence is maybe the best way for them . . . but . . . there are many possible ways to promote that ...

The topic of Debates 3 and 4 (D3 and D4) - the prevention of HIV/AIDS - was not unproblematic for the students, because the groups consisted of students from many different cultures and from various age groups. The attitudes varied according to the cultures, which was reflected for example in the following two examples. Example 6 shows how difficult abstinence can be for a mature, married man during his stay far from home and wife because of his studies, but he is willing to talk about his own personal life (ethos and pathos):

Ex. 6

D3 A1 I may abstain this time when I'm here in Europe but up to . . . next to . . next week I go to my country . . . Tanzania . . . I'll meet wife ... I'll have sex . . . then I need to know what is abstinence ... whenever I go back . . . I will have sex with someone who is already infected . . . I'll be already . . . I'll be affected . . . therefore I will abstain when I was here....

Crosscultural issues are also present in the following example in which Finnish female student (A3) is questioning the African male student (F4) about African young people's sex habits. The turn begins with the African student's rational argumentation and corresponds to the rhetorical use of logos. The Finnish female student is curious to know more about the forms of sexual behaviour in Africa and uses repeated questions in her speech.

Ex. 7

D3 F4 I think ... .er . . .educating people to use these . . condoms or other . . is . . more expensive than the ... dating them or telling them . . .to abstain . . .because the normal . . natural . . knowledge of the people is also there ... in most African countries . .. for example in my country . . . er . . . people naturally abstain from sex ... they keep their virginity ...

D3 A3 . . .until when . .

D3 F4 .until they get married. .

D3 A3 and when is that. .

D3 F4 . . in twenties . . twenty . . er . . twenty-two . .three .. could be more than that . .

Logos or the appeal to reason relies on logic or reason and often depends on the use of inductive or deductive reasoning. The term refers to the internal consistency of the message, the clarity of the claim, the logic of its reasons, and the effectiveness of its supporting evidence (Aristotle, 1997). In the debate situations, the students were well aware of the subject matter of the various themes of the debates, because they had learnt to prepare themselves for the most frequent topics of public health science during their two-semester course. In the next example, a Finnish male student refers to background information and bases his view on evidence:

Ex. 8

D3 F1 But ... if we promote abstinence ... it definitely should be like ... you said ... no no you should not have sex . . it is more . . . if we think of the prevention of HIV/AIDS . . then it's more effective . . . if we combine it to . . . er . . . the sexual health education . . . because I found some information that if is combined to these kind of measures ... er ... and even only the sex health education ... it promotes abstinence although it would not be the target of it .....

This was followed by another student of the same Group 'For' by appeals to both reason and emotions:

Ex. 9

D3 F4 I think we should increase the responsibility of . . hmm . . of the spread of HIV . . among people because . . . er . .. now there is . . quite unclear . . . legislation . . . because . . about . . . and responsibility of . . . for example ... taken sexual intercourse with positive HIV status of HIV information if . .. about . . . own HIV status and so on .... it's quite (unclear)

The third member of the same Group 'For' continues:

Ex. 10

D3 F2 ... and of course . . erm . . trying to ... er . . change the way . .er . . young people in ... er. . change their beliefs and their thoughts would be a good idea . . . in in . . .it's not anything that you should do when you're young ... erm . . . the same way that it's considered here in Finland . . . if . . . if a person very young age . . age has sex ... he or she . . . is considered to be a little bit . . erm . . I don't know how do you say . . er light headed . . 
In addition to showing appeals to reason, the above sequence of three Group 'For' students' arguments is a good example of a collaborative joint effort.

In addition to the use of ethos, pathos, and logos by the students, the data also show other relevant features of persuasive discourse such as persuasive messages, false arguments, and astonished questions. Persuasive messages are expected to include a clear idea or issue and provide supporting material (van Eemeren \& Houtlosser 2005). This can be seen in the following example:

Ex. 11

D3 F4 . . . for the first argument . . . most of the HIV cases in developing countries . . subsahara . . and Asian countries ... that covers over more than 60 per cent of the total HIV population in the world so . . in such areas HIV/AIDS is transmitted mainly by sexual intercourse . . . and . . abstinence in these cases . . very important to reduce the risk of HIV/AIDS in in . . the majority of those . . er . . risk population in developing countries . . . for your latter argument . . . HIV is highly prevalent in sexually active population . . . the young population from fifteen to twenty-five years ... so abstinence for this population is very important . .

D3 A2 . . . but I think that abstinence is . . er usually connected to sociocultural or religious . . issues like .. it considered that sex is taboo . . . and then it is not talked about and . . er . . I think it's better to give information ... er ... and just the condoms ... . and that kind of stuff . . . so bring responsible sexual behaviour and not telling not to have $\operatorname{sex} \ldots$

In the above example, the message of student F4 is an example of a well-organized persuasive statement, in which statistical information of the HIV/AIDS situation in the world is given and risks are mentioned. The counterargument made by student A2 refutes the argument of Group ' $\mathrm{F}$ '.

In persuasive discourse, the speakers are warned of false arguments (Cockcroft, 2005, p. 131). In the following example, a student from Group 'Against' launches topics that do not belong to the sphere of Debate 2:

Ex. 12

D2 A2 er ... we think that restriction is not a good way to come through alcohol abuse ... for example the same the . . sex education I can give you example . . in China ... no longer there are no longer sex education ... this theme is forbidden by the university or schools so . . but at that time the rate of teenage mothers are very high . . so . . er. . .for that . . ten years ago we began to spread sex education . . during education system in that education system not that . . teenage . . er teenage mother . . the rate is very low so you see tha restriction is not a good way to come through to better things. .

D2 F2 yeah . . the first thing is that education and then restriction .. what's wrong with the restriction

The student from Group 'For' (F2) seizes the opportunity to repeat the question 'What's wrong with the restriction?' One of the frequently used persuasion strategies in proponent groups was such repetition of the reinforcing question, uttered in a very emotional and sometimes demanding voice.

During the argumentation, the interesting phenomenon of the astonished or surprised question was used by the students. An example of this can be seen in the following example:

Ex. 13

D3 F4 I think .. .er . . .educating people to use these . . . condoms or other . . is . . .more expensive than the ... dating them or telling them . . .to abstain . . .because the normal . . natural . . knowledge of the people is also there ... in most African countries . .. for example in my country . . . er . . . people naturally abstain from sex ... they keep their virginity ...

D3 A3 . . until when . .

D3 F4 .until they get married..

D3 A3 and when is that. .

D3 F4 . . in twenties . . twenty . . er . twenty-two . .three .. could be more than that . .

At the same time, the above sequence is an illustrative example of interaction between speakers from different cultures, here an African male student (F4) and a Finnish female student (A3): first a longer argument, then the sequence of short questions and short answers with the aim of providing more evidence and questioning it. Selting (1996:, p. 231) has studied prosody as an activity-type distinctive cue in conversation and noticed that there is a difference between a 'normal' question and so-called 'surprised' or 'astonished' question. In the above extract the student has applied the same cue in a successful way. Debating means interaction between the proponent and the opponent, and in the above example the students achieve this requirement of the genre in question.

The first research question was 'What kinds of persuasive devices do the students have available in demanding debate situations in English?' (RQ1). In persuasive discourse, the first thing to start with is the use of rhetorical devices, i.e. ethos meaning personality and stance, pathos indicating emotional engagement, and logos meaning modelling and argumentation (Cockcroft, 2005). The features of persuasive discourse used in the debates consisted of the following: logical reasoning, repetition, questions, repeated questions, restructuring, and appeals to emotions. Logical reasoning, restructuring, and frequently used questions were the most frequently used means in both Finnish and non-Finnish student groups (see Table 1).

\section{B. Comparison of the Use of Persuasive Tools between Finnish and Non-Finnish Students}

In order to answer the second research question 'What kinds of differences are there in the use of persuasive means 
between Finnish and non-Finnish students' (RQ2), the results were examined from a comparative perspective. Table 1 shows the distribution of persuasive discourse features in Finnish $(\mathrm{N}=94)$ and non-Finnish students' $(\mathrm{N}=89)$ debating. Logical reasoning, restructuring, and appeals were the most frequently used markers of persuasive speech in debating. Since the number of Finnish participants $(\mathrm{N}=22)$ was higher than that of non-Finnish ones $(\mathrm{N}=12)$, the figures given in Table 1 have to be divided by the number of participants in order to obtain comparable results. These results, shown in Table 2 below, indicate that there were distinct differences in the use of the most frequent persuasive features by Finnish and non-Finnish participants.

TABLE 2.

THE USE OF PERSUASIVE TOOLS BY FINNISH AND NON-FINNISH PARTICIPANTS

\begin{tabular}{|l|l|l|}
\hline Form of persuasive behaviour & Finnish participants & Non-Finnish participants \\
\hline Logical reasoning & 1.45 & 2.4 \\
\hline Restructuring & 1.18 & 2.4 \\
\hline Appeals & 0.5 & 1.5 \\
\hline Repetition & 0,3 & 0,5 \\
\hline Repeated questions & 0,3 & 0,25 \\
\hline Questions & 0,4 & 0,3 \\
\hline
\end{tabular}

The results show that non-Finnish participants used these three persuasive means, logical reasoning, restructuring, and appeals, more frequently than the Finnish students: In Table 2, the figure showing the use of the persuasive feature was obtained by dividing the corresponding figure of Table 1 by the number of the participants of Finnish and non-Finnish groups. This gave the figure indicating the average use of the persuasive feature in each group. Repetition and repeated questions are typical features in argumentative speech: in these debates both questions and repetitions were used equally by Finnish participants and by non-Finnish participants.

Collaborative strategies are essential features in small group debating, and both Finnish and non-Finnish students used them in all debates. This may be based on the fact that role-games help creating a collaborative atmosphere, and students immediately adopt their roles in them ${ }^{1}$. Both Finnish and non-Finnish students were committed to their communicative task and their involvement was apparent. The theme of the debate is an essential factor while assessing the results. The first theme on alcohol legislation in Finland was not very motivating for the Finnish students, whereas the second theme on HIV/AIDS was interesting, but difficult. In any case, the limited number of participants has to be taken into consideration when assessing the results.

\section{DisCUSSION AND CONCLUSION}

The aim of the study was to study multinational university students' debating skills and to investigate how well they would manage in role games while acting out the roles of proponents or opponents in English. The first research question concerned the students' use of persuasive devices in debate and can be answered in the following way. According to the results, the students could use in their argumentation such rhetorical means as ethos, pathos, and logos: these were seen in their use of repetition, and questioning, restructuring and appeals, as well as in their use of logical reasoning, deduction, and induction, and ability to give examples. They were also able to give statistical information and use collaborative strategies in their debates. The second research question addressed crosscultural differences. The results show that the non-Finnish students used persuasive discourse markers, viz. logical reasoning, restructuring, and appeals more frequently than the Finnish students.

These results can be compared with the results of an earlier study showing that the non-Finnish students had more and a wider array of paralinguistic tools available than the Finnish students to support their argumentation (see Metsämäki 2011). Gestures, which were always connected with speech, were the most frequently used paralinguistic means in these debates. The use of gestures has not been very common in the Finnish speech culture, although their use is increasing as a result of ongoing cultural change (Wilkins \& Isotalus, 2009, p. 6). The use of assertive voice is another paralinguistic means used more by non-Finnish students than Finnish students (see Metsämäki 2011). This means that Finnish students who are used to the monotonous Finnish speech communication, may find it problematic to use the English intonation or assertive voice in a natural way when speaking English (Wilkins \& Isotalus, 2009, p. 1 12). While the crosscultural differences in the use of rhetorical strategies appear limited, the relationship between gender and argumentation needs further study. The results indicate that female students used more appeals to emotions whereas male students, particularly non-Finnish males, used more effective logical reasoning in their debating. It has been shown in earlier research on Finnish speech culture (Wilkins \& Isostalus, 2009, p. 63) that it is very message-centred. The results of this study reveal the same feature, particularly in the turns by several Finnish male participants.

The aim of persuasive discourse is to alter the old beliefs, attitudes, and opinions and create new attitudes and beliefs. In the case of a role game it is impossible to say whether the participants achieved changing the opinions of the opposing team, because they realized that the whole effort was a game. The students seemed to be very pleased with the final result, because they had tried their best and they had been committed to their task. On the basis of the results it can be suggested that debates provide good good tools for teaching foreign languages at the university level. Awareness of

\footnotetext{
1 Kaipasi pehmennystä ilmaisuun.
} 
new problem-solving methods and new techniques helps both the teaching personnel to promote language teaching and the students to face new, challenging learning environments. Furthermore, new innovative research is needed to address crosscultural differences among multinational university students in the globalizing academic world.

\section{REFERENCES}

[1] Aristotle. (1926). The art of rhetoric. Trans. J.H. Freese. Loeb Classical Library. .London: Heinemann.

[2] Aristotle. (1997). Retoriikka. Runousoppi. Trans. P. Hohti. Helsinki: Gaudeamus.

[3] Austin, J.L. (1976). How to do things with words. London: Oxford University Press.

[4] Burgoon, M. \& E.P. Bettinghaus. (1984). Persuasive message strategies. In M. E. Roloff and G. R. Miller (eds.), Persuasion: New directions in theory and research. London: Sage. 141-169.

[5] Cockcroft R. \& S. (2005). Persuading people: An introduction to rhetoric. New York: Palgrave Macmillan.

[6] Fairclough, N. (2001). Language and power. Harlow: Pearson Education.

[7] Fulcher, G. and F. Davidson. (2007). Language testing and assessment. New York: Routledge.

[8] Goffman, E. (1981). Forms of talk. Philadelphia: University of Pennsylvania Press.

[9] Grice, H.P. (1975). Logic and conversation. In. P. Cole and J. Morgan (eds.), Syntax and semantics. Vol. 3. New York: Academic Press, 41-58.

[10] Hovland, C.E., Janis, I.L., \& Kelley, H.H. (1953). Communications and persuasion. Studies in opinion change. New Haven, CT. Yale University Press.

[11] Hutchby, I. (1996). Confrontation talk: Arguments, asymmetries and power on talk radio. New Jersey: Lawrence Erlbaum.

[12] Kakkuri-Knuuttila, M.-L. \& I. Halonen. (2007). Argumentaatioanalyysi ja hyvän argumentin ehdot. In M.-L. Kakkuri-Knuuttila (ed.) Argumentti ja kritiikki: Lukemisen, keskustelun ja vakuuttamisen taidot. Helsinki: Gaudeamus

[13] Levine, R. (2003). The power of persuasion: How we are bought and sold. Oxford: Wiley.

[14] Metsämäki, M. (2011). Paralinguistic means and their role in university students' L2 debate. Lingua Americana 28 (forthcoming).

[15] Roloff, M. E. \& G. R. Miller (eds.). (1984). Persuasion: New directions in theory and research. London: Sage.

[16] Sallinen-Kuparinen, A. (1986). Finnish communication reticence: Perceptions and self-reported behaviour. Jyväskylä: University of Jyväskylä.

[17] Sallinen, A. (1994). Suomalaisten kommunikoijakuva (The Self-image of Finns as communicators). In P. Isotalus (ed.) Puheesta ja vuorovaikutuksesta. Jyväskylä. University of Jyväskylä. 73-84.

[18] Searle, J.R. (1999 [1969]). Speech acts: An essay in the philosophy of language. Cambridge: Cambridge University Press.

[19] Selting, M. \& E. Couper-Kuhlen (eds.). (1996). Prosody in Conversation. Cambridge: Cambridge University Press.

[20] Sherif, M. \& C.I. Hovland. (1961). Social Judgement: Assimilation and Contrast effects in communication and attitude change. Westport, CT: Greenwood Press.

[21] Sherif, C.W., Sherif, M. and R. E. Nebergall. (1965) Attitude and attitude change: The 'social judgement-involvement approach'. Philadelphia. W.B. Saunders.

[22] Simons, H.W., Morreale, J., \& Gronbeck, B. (2001). Persuasion in society. Thousand Oaks, Calif.: Sage Publications. 25-39.

[23] Tannen, D. (1999). The argument culture changing the way we argue. London: The Palimpsest Book Production Ltd.

[24] Tarasti, E. (2008). Retoriikka ja musiikin diskurssi. Synteesi: Taiteidenvälisen tutkimuksen aikakauslehti, 2-26.

[25] Ylikoski, M. (1987). Väittele viisaasti. Porvoo: WSOY.

[26] Walter, O.M. (1966). Speaking to inform and persuade. New York: Macmillan.

[27] Van Eemeren, H. and P. Houtlosser (eds.). (2005). Argumentation in practice. Amsterdam: John Benjamins.

[28] Wilkins, R. and P. Isotalus. (2009). Speech culture in Finland. Plymouth: University Press of America.

Maija Metsämäki was born in Kuopio, Finland and she is a university lecturer, retired. Her degrees are BSc, Econ. Helsinki School of Economics, Helsinki, Finland, 1956, MA, English and French Philology, Education, University of Jyväskylä, Jyväskylä, Finland, 1974, PhD student of Applied and Sociolinguistics, University of Eastern Finland, Joensuu, Finland.

She has worked as a language teacher in many levels of schools and adult institutions in Imatra, Lappeenranta, and Kuopio in Finland and she retired from her post as a university lecturer and the Head of the Language Centre of the former University of Kuopio in 1997. After that she has had teacher posts in Sibelius-Academy and at the University of Applied Sciences in Kuopio. She was working as an assessor for the National Language Tests at the University of Jyväskylä during 1991 - 2007. She was a Regional Advisor of teachers of foreign languages and of adult education in the County of Kuopio in 1975-1980. She has published the following articles: 'Inflluencing through the Language - University Students' Argumentation Strategies', AFinLA Yearbook 2009. http//:www.jyu,fi/hum/laitokset/solki/afinla/julkaisut. 'Towards Effective Communication in Health and Social Sector". Essays in honour of Guy Bäckman, ed. J. Laurinkari', 2010. Europäischer Hochschulverlag GmbH \& Co. KG, Bremen 'Paralinguistic Means and their Role in University Students' ESL Debate'. 2011. Lingua Americana, Vol. 28 (forthcoming).

Ms. Metsämäki is a member of Association Finlandaise de la Linguistique Appliquée, Finland. Ms. Metsämäki is a member of the International Semiotics Institute (IAAS-AIS), Imatra, Finland. 